\title{
EFEKTIFITAS TEKNIK SITZ BATH UNTUK MENGURANGI NYERI RUPTURE PERINEUM PADA IBU NIFAS DI PRAKTIK MANDIRI BIDAN DINCE SYAFRINA, SST TAHUN 2019
}

\author{
Octa Dwienda Ristica, M.Kes ${ }^{1}$, Rita Afni, SST, M.Kes ${ }^{2}$ \\ STIKes Hangtuah Pekanbaru \\ Email: octadwienda@htp.ac.id
}

\begin{abstract}
Every mother who goes through labor with a perineal rupture will feel pain. Efforts to prevent and overcome this pain can be done by using the sitz bath technique. The aim of this study was to determine the effectiveness of the sitz bath technique to reduce pain in the perineal rupture of postpartum mothers at the Independent Practice of Midwife Dince Syafrina, SST. This type of research uses a Quasi experimental method with a sampling technique or sampling that is purposive sampling. The population in this study were 35 postpartum mothers with perineal injuries at the Dince Syafrina Midwifery Independent Practice, SST Pekanbaru. Data analysis in this study was univariate and bivariate analysis. The results showed that the majority of respondents before being given perineal wound pain reduction therapy with the sitz bath technique experienced a pain intensity of 7, namely 13 people (37.1\%). And after being given perineal wound pain reduction therapy with the sitz bath technique, experienced a pain intensity of 6, namely 12 people (34.3\%). The conclusion of this study is that the average pain intensity of perineal injury in postpartum mothers in the first measurement is 6.43 (moderate pain), while the average pain intensity in the second measurement is 4.69 (moderate pain), it is concluded that there is an effect giving therapy with the sitz bath technique for perineal wound pain in postpartum mothers. The suggestion of this research is that it is hoped that health workers can overcome perineal wound pain, namely not only providing pharmacological therapy but also combining it with the provision of pain reduction therapy with sitz bath techniques in dealing with perineal wound pain.
\end{abstract}

Key words: Effectiveness, Sitz bath, Perineal Rupture Pain

\begin{abstract}
ABSTRAK
Setiap ibu yang menjalani proses persalinan dengan mendapatkan rupture perineum akan merasakan nyeri. Upaya pencegahan dan mengatasi nyeri ini bisa dengan pemanfaatan teknik sitz bath Tujuan penelitian ini untuk mengetahui efektifitas teknik sitz bath untuk mengurangi nyeri rupture perineum pada ibu nifas di Praktik Mandiri Bidan Dince Syafrina, SST. Jenis penelitian ini menggunakan metode Quasi experimental dengan teknik pengambilan sampel atau sampling yaitu Purposive sampling. Populasi dalam penelitian ini adalah ibu Nifas dengan luka perineum di Praktik Mandiri Bidan Dince Syafrina, SST Pekanbaru sebanyak 35 orang. Analisa data pada penelitian ini adalah analisa univariat dan bivariate. Hasil penelitian menunjukkan mayoritas responden sebelum diberikan terapi pengurang nyeri luka perineum dengan tekhnik sitz bath mengalami intensitas nyeri 7 yakni berjumlah 13 orang ( $37,1 \%$ ). Dan sesudah diberikan terapi pengurang nyeri luka perineum dengan tekhnik sitz bath, mengalami intensitas nyeri 6 yakni berjumlah 12 orang ( $34.3 \%$ ). kesimpulan penelitian ini adalah didapatkan bahwa rata-rata intensitas nyeri luka perineum pada ibu nifas pada pengukuran pertama adalah 6,43 (nyeri sedang), sedangkan rata-rata intensitas nyeri pada pengukuran kedua adalah 4,69 (nyeri sedang), maka
\end{abstract}


disimpulkan ada pengaruh pemberian terapi dengan tekhnik sitz bath terhadap nyeri luka perineum pada ibu nifas. Saran penelitian ini diharapkan kepada tenaga kesehatan dapat mengatasi nyeri luka perineum yaitu bukan hanya memberikan terapi farmakologis namun dapat mengkombinasikan dengan pemberian terapi pengurang nyeri dengan tekhnik sitz bath dalam mengatasi nyeri luka perineum.

Kata kunci

\section{PENDAHULUAN}

Persalinan adalah proses pengeluaran hasil konsepsi (janin dan ari) yang telah cukup bulan atau telah dapat hidup di luar kandungan melalui jalan lahir, dengan bantuan atau tanpa bantuan. Dalam persalinan sering terjadi perlukaan pada perineum baik itu karena robekan spontan maupun episiotomi (Fatimah \& Lestari, 2019). Pada tahun 2017 di Indonesia robekan perineum/rupture perineum dialami oleh $75 \%$ ibu melahirkan pervaginam, ditemukan dari total 1951 ibu yang melahirkan spontan pervaginam, $57 \%$ ibu mendapatkan jahitan perineum yaitu 28\% karena episiotomi dan 29\% karena robekan spontan (Kementerian Kesehatan Republik Indonesia, 2017).

Ruptur perineum didefinisikan sebagai robekan yang terjadi ketika bayi lahir, baik secara spontan maupun dengan alat atau tindakan (Fatimah \& Lestari, 2019). Rupture perineum merupakan laserasi atau luka yang terjadi disepanjang jalan lahir (perineum) akibat proses persalinan yang dapat terjadi secara disengaja (episiotomi) atau tidak disengaja. Ruptur perineum merupakan penyebab keempat perdarahan setelah inversio uteri yang terjadi pada persalinan pertama atau pada persalinan berikutnya (Maritalia, 2012).

Setiap ibu yang menjalani proses persalinan dengan mendapatkan rupture perineum akan merasakan nyeri, nyeri yang dirasakan pada setiap ibu dengan rupture perineum menimbulkan dampak yang tidak menyenangkan seperti kesakitan dan rasa takut untuk bergerak, setelah pasca melahirkan sehingga dapat mengakibatkan banyak masalah diantaranya sub involusi uterus, pengeluaran lochea yang tak lancar dan perdarahan post partum (Potter \& Perry, 2012).

Adapun peran bidan pada penanganan ibu nifas dengan nyeri akibat rupture perineum adalah dengan menganjurkan ibu untuk mobilisasi dini. Pada keadaan dimana bagian tubuh mengalami robekan maka saraf disekitar luka akan menjadi sangat peka dan timbul nyeri, namun semakin aktif bergerak, maka rasa nyeri akan semakin berkurang. Lakukan relaksasi nafas panjang saat latihan duduk 
atau jalan agar mengurangi nyeri. Selain itu anjurkan ibu untuk melakukan perawatan luka perineum dengan cara mencuci daerah genetal dengan air dan sabun setiap kali habis BAK/BAB yang dimulai dengan mencuci bagian depan, baru kemudian daerah anus. Sebelum dan sesudahnya ibu dianjurkan untuk mencuci tangan. Pembalut hendaknya diganti minimal 2 kali sehari atau diganti setiap ibu merasa sudah penuh(Walyani \& Purwoastuti, 2015).

Selain itu, terapi atau tindakan penanganan nyeri dapat dilakukan secara farmakologis dan nonfarmakologis.Penanganan nyeri secara farmakologis yaitu dengan menggunakan obat analgesik. Tetapi pemberian analgesik masih menimbulkan pertentangan karena menyebabkan efek samping pada penggunanya. Selain itu walaupun analgesik dapat menghilangkan nyeri dengan efektif, tenaga kesehatan cenderung tidak melakukan upaya analgesik dalam penanganan nyeri karena informasi obat yang tidak benar, serta adanya kekhawatiran klien akan mengalami ketagihan obat, cemas akan melakukan kesalahan dalam menggunakan analgesik(Potter \& Perry, 2012).

Sedangkan secara nonfarmakologis lebih aman diterapkan karena mempunyai risiko yang lebih kecil, tidak menimbulkan efek samping serta menggunakan proses fisiologis. Terapi non farmakologi yang dapat diberikan untuk mengurangi nyeri antara lain distraksi, biofeedback, hypnosis diri, mengurangi presepsi nyeri, stimulasi kutaneus, sitz bath, serta massase (Potter \& Perry, 2012). Salah satu metode non farmakologi pilihan yang bersifat sederhana, murah, simple, efektif, dan tanpa efek merugikan yang dapat digunakan untuk mengatasi nyeri dan ketidaknyamanan akibat rupture perineum, serta dapat meningkatkan sirkulasi dan mendukung penyembuhan luka perineum adalah dengan pemanfaatan teknik sitz bath (Saputri et al., 2013).

Sitz bath adalah mandi rendam duduk (duduk disebuah bak berisi air hangat) yang berfungsi untuk memberikan panas lembab ke area pelvis, perineum, dan/atau perianal.Salah satu manfaat sitz bath adalah menurunkan rasa nyeri dan kaku pada perineum.Terapi ini paling sering digunakan setelah kelahiran bayi atau bedah rektal/perineal (Rosdahl \& Kowalski, 2014).

\section{METODE STUDI KASUS}

Jenis penelitian yang dilakukan adalah Quasi experimental (experiment semu), populasi penelitian ini adalah adalah ibu 
Nifas dengan luka perineum di Praktik Mandiri Bidan Dince Syafrina, SST Pekanbaru dari Oktober 2019 Desember 2019 dengan jumlah sample sebanyak 35 orang. Pengambilan sample dilakukan dengan teknik Purposive sampling. Data yang digunakan adalah data primer dan sekunder terhadap responden. Pengolahan data dilakukan dengan tahap-tahap editing, coding, entry, cleaning dan processing. Analisa data yang dilakukan adalah analisa univariat dan analisa bivariat

\section{HASIL}

\section{Hasil Univariat}

Tabel 1.

\section{Karakteristik Responden Berdasarkan}

intensitas nyeri sebelum pemberian terapi dengan tekhnik sitz bath

\begin{tabular}{ccc}
\hline Intensitas & Frekuensi(N) & Persentase \\
\hline 2 & 1 & 2.9 \\
3 & 3 & 8.6 \\
4 & 1 & 2.9 \\
5 & 6 & 17.1 \\
7 & 13 & 37.1 \\
8 & 10 & 28.6 \\
9 & 1 & 2.9 \\
\hline Total & 35 & 100.0 \\
\hline
\end{tabular}

Berdasarkan tabel 1 diatas mayoritas responden sebelum diberikan terapi pengurang nyeri luka perineum dengan tekhnik sitz bath mengalami intensitas nyeri 7 yakni berjumlah 13 orang ( 37,1 $\%)$

\section{Tabel 2}

Karakteristik Responden Berdasarkan intensitas nyeri sesudah diberikan terapi dengan tekhnik sitz bath

\begin{tabular}{ccc}
\hline Intensitas & Frekuensi(N) & Persentase \\
\hline 1 & 2 & 5.7 \\
2 & 2 & 5.7 \\
3 & 4 & 11.4 \\
4 & 5 & 14.3 \\
5 & 8 & 22.9 \\
\hline 6 & 12 & 34.3 \\
\hline 7 & 2 & 5.7 \\
\hline Total & 35 & 100.0 \\
\hline
\end{tabular}

Berdasarkan tabel 2 diatas mayoritas responden sesudah diberikan terapi pengurang nyeri luka perineum dengan tekhnik sitz bath, mengalami intensitas nyeri 6 yakni berjumlah 12 orang ( 34.3 $\%)$

\section{Analisis Bivariat}

Tabel 3.

Paired Samples Statistics

\begin{tabular}{|c|c|c|c|c|c|}
\hline & $\mathrm{N}$ & Mean & $\begin{array}{c}\text { Std. } \\
\text { Deviation }\end{array}$ & $\begin{array}{c}\text { Std.error } \\
\text { mean }\end{array}$ & P.Value \\
\hline $\begin{array}{l}\text { Sebelum } \\
\text { diberikan }\end{array}$ & \multirow{2}{*}{35} & 6.43 & 1.787 & 0.302 & \multirow{2}{*}{0,000} \\
\hline $\begin{array}{l}\text { Sesudah } \\
\text { diberikan }\end{array}$ & & 4.69 & 1.605 & 0.271 & \\
\hline
\end{tabular}

Berdasarkan tabel 3 paired samples statistics, didapatkan hasil bahwa rata-rata intensitas nyeri luka perineum pada ibu nifas pada pengukuran pertama adalah 6,43 (nyeri sedang), sedangkan 
rata-rata intensitas nyeri pada pengukuran kedua adalah 4,69 (nyeri sedang)

Pada test statistik, diperoleh nilai $\mathrm{p}=0,000$ sehingga Ho ditolak maka disimpulkan ada pengaruh pemberian terapi dengan tekhnik sitz bath terhadap nyeri luka perineum pada ibu nifas ( $p$ $<0,000)$

\section{PEMBAHASAN}

Analisa Perbedaan Intensitas Nyeri Sebelum (Pre-Test) Dan Sesudah (PostTest) pemberian terapi dengan tekhnik sitz bath, intensitas nyeri pada data pre-test sebelum pemberian terapi dengan tekhnik sitz bath tertinggi adalah intensitas nyeri 7 yang tergolong kedalam kelompok nyeri berat sebanyak 13 responden $(37,1 \%)$, intensitas nyeri terendah yaitu pada intensitas nyeri 2, 3 yang tergolong pada kelompok nyeri ringan sebanyak 1 responden $(2,9 \%)$ dan intensitas nyeri 9 yang tergolong pada kelompok nyeri berat sebanyak 1 responden $(2,9 \%)$ dan pada data post-test sesudah pemberian terapi dengan tekhnik sitz bath intensitas nyeri tertinggi adalah intensitas nyeri 6 yang tergolong pada kelompok nyeri sedang sebanyak 12 responden $(34,3 \%)$, intensitas nyeri terendah yaitu intensitas nyeri 1 dan 2 yang tergolong pada kelompok nyeri ringan sebanyak 2 responden $(5,7 \%)$ dan intensitas nyeri 7 yang tergolong pada kelompok nyeri berat sebanyak 2 responden $(5,7 \%)$. Dari hasil analisa data dengan menggunakan uji $\mathrm{t}$ dependent untuk mengetahui kekuatan pengaruh pemberian terapi dengan tekhnik sitz bath terhadap intensitas nyeri luka perineum menghasilkan rata-rata (mean) intensitas nyeri sebelum diberikan terapi dengan tekhnik sitz bath sebesar 6,43 dengan standar deviasi 1,787. Rata-rata (mean) intensitas nyeri sesudah diberikan terapi dengan tekhnik sitz bath sebesar 4,69 dengan standar deviasi 1,605. Dari hasil uji statistik didapatkan nilai p Value $(\alpha)$ sebesar 0,000 .

Dengan demikian nilai $\mathrm{p}$ Value lebih kecil dari 0,5 sehingga Ho ditolak, dapat disimpulkan bahwa terdapat perbedaan rata-rata skala nyeri luka perineum yang bermakna antara sebelum pemberian terapi dengan tekhnik sitz bath dan sesudah pemberian terapi dengan tekhnik sitz bath dan dapat disimpulkan bahwa hipotesisnya ada pengaruh pemberian terapi dengan tekhnik sitz bath terhadap perubahan intensitas nyeri luka perineum pada ibu nifas di Praktik Mandiri Bidan Dince Syafrina, SST Pekanbaru.

Rupture adalah robeknya atau koyaknya jaringan secara paksa. Rupture perineum adalah robekan yang terjadi ketika bayi lahir, baik secara spontan 
maupun dengan alat atau tindakan episiotomy (Wiknjosastro, 2008).

Rupture perineum sering kali menimbulkan ketidaknyamanan pada ibu post partum. Ketidaknyamanan tersebut disebabkan oleh rupture dan jahitan terhadap rupture tersebut. Kebanyakan ibu merasa takut untuk menyentuh bahkan membersihkan luka pada perineum karena nyeri yang dirasakan. Nyeri adalah pengalaman sensori dan emosional yang tidak menyenangkan yang timbul akibat kerusakan jaringan aktual atau potensial atau dijelaskan dengan istilah kerusakan tersebut (Doenges et al., 2015).

Nyeri yang dirasakan oleh ibu post partum pada bagian perineum disebabkan karena luka perineum baik luka robekan spontan atau luka yang di buat seperti episiotomi, dapat menimbulkan ketidaknyamanan seperti kesakitan dan takut bergerak, kesulitan pada saat buang air besar dan buang air kecil, mengganggu aktifitas sehari-hari antara lain dalam hal mengurus bayi, mengerjakan pekerjaan rumah tangga, sosialisasi dengan lingkungan dan masyarakat, serta menghambat ketika ibu akan mulai bekerja, bahkan rasa nyeri tersebut dapat pula menyebabkan insomnia.

Mengingat permasalahan yang dapat timbul sebagai akibat dari robekan perineum pada saat melahirkan, maka penanganan setiap kejadian robekan perineum harus segera dilakukan secara berkualitas guna meminimalkan kemungkinan keluhan yang menyertainya, seperti nyeri luka perineum yang sering di rasakan.

Terapi atau tindakan penanganan nyeri dapat dilakukan secara farmakologis dan nonfarmakologis.Penanganan nyeri secara farmakologis yaitu dengan menggunakan obat analgesik. Tetapi pemberian analgesik masih menimbulkan pertentangan karena menyebabkan efek samping pada penggunanya. Selain itu walaupun analgesik dapat menghilangkan nyeri dengan efektif, tenaga kesehatan cenderung tidak melakukan upaya analgesik dalam penanganan nyeri karena informasi obat yang tidak benar, serta adanya kekhawatiran klien akan mengalami ketagihan obat, cemas akan melakukan kesalahan dalam menggunakan analgesik(Potter \& Perry, 2012)

Sedangkan secara nonfarmakologis lebih aman diterapkan karena mempunyai risiko yang lebih kecil, tidak menimbulkan efek samping serta menggunakan proses fisiologis. Terapi non farmakologi yang dapat diberikan untuk mengurangi nyeri antara lain distraksi, biofeedback, hypnosis diri, 
mengurangi presepsi nyeri, stimulasi kutaneus, sitz bath, serta massase (Potter \& Perry, 2012). Salah satu metode non farmakologi pilihan yang bersifat sederhana, murah, simple, efektif, dan tanpa efek merugikan yang dapat digunakan untuk mengatasi nyeri dan ketidaknyamanan akibat rupture perineum, serta dapat meningkatkan sirkulasi dan mendukung penyembuhan luka perineum adalah dengan pemanfaatan teknik sitz bath (Saputri et al., 2013).

Sitz bath adalah mandi rendam duduk (duduk disebuah bak berisi air hangat) yang berfungsi untuk memberikan panas lembab ke area pelvis, perineum, dan/atau perianal.Salah satu manfaat sitz bath adalah menurunkan rasa nyeri dan kaku pada perineum.Terapi ini paling sering digunakan setelah kelahiran bayi atau bedah rektal/perineal (Rosdahl \& Kowalski, 2014).

Penelitian ini sesuai dengan penelitian yang dilakukan oleh (Tintasia et al., 2015) tentang "Pengaruh Pelatihan Sitz bath Terhadap Intensitas Nyeri pada Ibu Nifas Post Episiotomi” yaitu skala nyeri tertinggi sebelum diberikan pelatihan sitz bath yaitu skala 9 sedangkan setelah diberikan perlakuan sitz bath intensitas nyeri mengalami perubahan dengan skala tertinggi adalah skala 5. Artinya, terjadi penurunan intensitas nyeri pada kelompok intervensi dengan selisih antara sebelum dan sesudah diberikan perlakuan sitz bath berdasarkan skala nyeri adalah 4 .

Penelitian ini juga sejalan dengan hasil penelitian(Saputri et al., 2013)tentang "Intensitas Nyeri Perineum pada Ibu Post Partum dengan Terapi Rendam Duduk Air Hangat" didapatkan dari 11 responden yang belum diberi terapi rendam duduk air hangat, diantaranya $6 \mathrm{ibu}(54,6 \%)$ mengalami nyeri sedang. Dan setelah diberi terapi rendam duduk air hangat didapatkan hasil sebanyak 8 ibu (72,7\%) yang mengalami nyeri ringan.

\section{KESIMPULAN}

Mayoritas responden sebelum diberikan terapi pengurang nyeri luka perineum dengan tekhnik sitz bath, mengalami intensitas nyeri 7 yakni berjumlah 13 orang ( $37,1 \%$ ). Mayoritas responden sesudah diberikan terapi pengurang nyeri luka perineum dengan tekhnik sitz bath, mengalami intensitas nyeri 6 yakni berjumlah 12 orang ( 34.3 $\%)$. Hasil bahwa rata-rata intensitas nyeri luka perineum pada pengukuran pertama adalah 6,43 (nyeri sedang), sedangkan rata-rata intensitas nyeri pada pengukuran kedua adalah 4,69 (nyeri sedang). Pada test statistik, diperoleh nilai $\mathrm{p}=0,000$ sehingga Ho ditolak maka disimpulkan 
ada pengaruh pemberian terapi dengan tekhnik sitz bath terhadap nyeri luka perineum pada ibu nifas ( $p<0,000$ )

\section{SARAN}

Berdasarkan hasil penelitian ini diharapkan dalam melakukan asuhan kebidanan dapat merumuskan cara dalam mengatasi nyeri luka perineum yaitu bukan hanya memberikan terapi farmakologis namun dapat mengkombinasikan dengan pemberian terapi pengurang nyeri dengan tekhnik sitz bath dalam mengatasi nyeri luka perineum atau jenis-jenis terapi lainnya.

\section{DAFTAR PUSTAKA}

Doenges, M. E., Moorhouse, M. F., \& Murr, A. C. (2015). Manual Diagnosis Keperawatan (P. E. Karyuni, E. A. Mardella, E. Wahyuningsih, \& M. Mulyaningrum (eds.)). Buku Kedokteran EGC.

Fatimah, \& Lestari, P. (2019). Pijat Perineum (D. Rachmawati (ed.)). Pustaka Baru Press.

Kementerian Kesehatan Republik Indonesia. (2017). Profil Kesehatan
Indonesia Tahun 2017. 496.

Maritalia, D. (2012). Asuhan Kebidanan Nifas dan Menyusui (S. Riyadi (ed.)). Pustaka Pelajar.

Potter, P. A., \& Perry, A. G. (2012). Fundamental Keperawatan (M. Ester, D. Yulianti, \& I. Parulina (eds.)). Buku Kedokteran EGC.

Rosdahl, C. B., \& Kowalski, M. T. (2014). Keperawatan Dasar (E. A. Mardella \& D. Yulianti (eds.)). Buku Kedokteran EGC.

Saputri, M. A., Mansur, H., \& Rahayu, S. (2013). Intensitas Nyeri Perineum Pada Ibu Post Partum Dengan Terapi Rendam Duduk Air Es dan Air Hangat. Poltekes Kemenkes Malang, 10.

Tintasia, Natosba, J., \& Girsang, B. M. (2015). Pengaruh Pelatihan Sitz Bath Terhadap Intensitas Nyeri Pada Ibu Nifas Post Episiotomi. PSIK Fakultas Kedokteran Universitas Sriwijaya, 14.

Walyani, E. S., \& Purwoastuti, T. E. (2015). Asuhan Kebidanan Masa Nifas dan Menyusui. Pustaka Baru Press. 